\title{
Structure and functions of plant calcium-dependent protein kinases
}

\author{
Maria Klimecka ${ }^{\bowtie}$ and Grażyna Muszyńska \\ Plant Biochemistry Department, Institute of Biochemistry and Biophysics, Polish Academy of Sciences, \\ Warszawa, Poland
}

Received: 26 January, 2007; revised: 18 March, 2007; accepted: 20 March, 2007 available on-line: 19 April, 2007

\begin{abstract}
Calcium ions as second messengers play an essential role in many important cellular processes. In plants, transient changes in calcium content in the cytosol (calcium signatures) have been observed during growth, development and under stress conditions. Such diverse functions require many different calcium sensors. One of the largest and most differentiated group of calcium sensors are protein kinases, among them calcium-dependent protein kinases (CDPKs) which were identified only in plants and protists. CDPKs have a regulatory domain which is able to bind calcium ions. For regulation of CDPKs activities not only calcium ions but also specific phospholipids and autophosphorylation are responsible. CDPKs have many different substrates, which reflects the diversity of their functions. Potential protein substrates of CDPK are involved in carbon and nitrogen metabolism, phospholipid synthesis, defense responses, ion and water transport, cytoskeleton organization, transcription and hormone responses. Presently, participation of CDPKs in stress signal transduction pathways (e.g., cold, drought, high salinity, wounding) is intensively studied in many laboratories. An intriguing, but still not fully clarified problem is the cross-talk via CDPKs among different signaling pathways that enables signal integration at different levels and ensure appropriate downstream responses.
\end{abstract}

Keywords: calcium, plant protein kinases, signal transduction, stress responses, cross-talk

\section{ROLE OF CALCIUM IONS AS SENSORS IN PLANT SIGNAL TRANSDUCTION}

In plants, calcium ions are the second messenger coupling physiological responses to external and developmental signals (Reddy \& Reddy, 2004). Changes in cytosolic free calcium ion concentration are apparent during transduction of abiotic stimuli including light, low and high temperature, touch, hyperosmotic and oxidative stresses and also in the case of biotic stimuli including fungal elicitors and nodulation (Nod) factors (Rudd \& Franklin-Tong, 2001; Sanders et al., 2002). It has been suggested that information encrypted in the stimulus can induce an increase of free calcium ions in the cytosol and helps to define the response. The stimulus-specific increases in free cytosolic $\mathrm{Ca}^{2+}$ are called calcium signatures (Evans et al., 2001). Any given $\mathrm{Ca}^{2+}$-mediated cellular process begins with the generation of such signal-specific calcium signature in the cytoplasm (or nucleus) by a synchronized activity of channels, pumps and transporters. Changes in cy-

\footnotetext{
$\square$ Corresponding author: M. Klimecka, Plant Biochemistry Department, Institute of Biochemistry and Biophysics, Polish Academy of Sciences, A. Pawińskiego 5a, 02-106 Warszawa, Poland; e-mail: majkak@ibb.waw.pl

Abbreviations: ABA, abscisic acid; ACC, 1-amino-cyclopropane-1-carboxylic acid; CBL, calcineurin B-like proteins; CaM, calmodulin; CaMKs, $\mathrm{Ca}^{2+} /$ calmodulin dependent kinases; CaM-LD, calmodulin like-domain; $\mathrm{CCaMKs}_{\mathrm{Ca}} \mathrm{Ca}^{2+} \mathrm{or} \mathrm{Ca}^{2+} / \mathrm{cal}^{-}$ modulin regulated kinases; CDPK/SnRK, calcium-dependent protein kinase/sucrose non fermenting related kinases family; CRKs, CDPK related kinases; ER, endoplasmic reticulum; EST, expressed sequence tag; GA, gibberelic acid; IAA, indole-3-acetic acid; JA, jasmonic acid; LysoPC, L- $\alpha$-lysophosphatidylcholine; MAPKs, mitogen-activated protein kinases; MeJA, methyl jasmonate; PA, phosphatidic acid; (1,2-diacyl-sn-glycero-3-phosphate); PC, phosphatidylcholine; (1,2-diacyl-sn-glycero-3-phosphocholine); PE, L- $\alpha$-phosphatidylethanolamine; PEPRKs, PPCK-related kinases; PI, phosphatidylinositol; (1,2-diacyl-sn-glycero-3-phospho-(1-D-myo-inositol)); PPCKs, phosphoenolopyruvate carboxylase kinases; PRs, pathogenesis-related genes; PS, phosphatidylserine; (1,2-diacyl-sn-glycero-3-phospho-L-serine); SnRKs 1, 2, 3, SNF1-related kinases, type 1, 2 and 3; WR, wound-related genes.
} 
tosolic free calcium ion level are sensed by a specific set of proteins named calcium sensors. The first class of sensors without any responder domains (e.g., calmodulin and calcineurin B-like proteins) bind $\mathrm{Ca}^{2+}$ and undergo conformational changes that in turn regulate the activity/function of a variety of target proteins or regulate gene expression. Such sensors are called "sensor relays". Sensors of the second group are called "responders" as they have effector domains (e.g., protein kinase or phospholipase domain) through which they relay the message to their downstream targets (Reddy \& Reddy, 2004).

The $\mathrm{Ca}^{2+}$ binding EF-hand motif is the predominant calcium sensor. This motif is highly conserved. The EF-hand motif is a 29 aa helix-loop-helix structure which resembles that of a hand having the index finger and thumb (the two helices) extended at roughly right angles from the rest of the fingers, which are curled towards the palm (the loop) (Harmon, 2003). The loop in each EF-hand motif consists of 12 residues with a pattern of conserved residues that coordinate the calcium ion. The EF-hand modules bind $\mathrm{Ca}^{2+}$ ions in the loops and undergo large conformational changes that result in the exposure of hydrophobic pockets, which in turn facilitates interactions of the protein with a variety of protein partners. The presence of pairs of EF-hand motifs in proteins increases their stability and affinity for calcium (Reddy \& Reddy, 2004). A study of 300 EF-hand proteins from all kingdoms of eukaryotes has shown that most of them bind $\mathrm{Ca}^{2+}$ with $K_{\mathrm{d}} \mathrm{s}$ in the range of 0.1 to $1 \mu \mathrm{M}$ (Kawasaki et al., 1998). The EF-hand proteins found in plants include calmodulin $(\mathrm{CaM})$, calcineurine B-like proteins (called CBL/SCaBPs) and protein kinases (Hrabak et al., 2003).

\section{PLANT PROTEIN KINASES AS CALCIUM SENSORS}

Plant protein kinases are a large and differentiated group of calcium sensors. The CDPK/SnRK family of protein kinases was defined by a sequence similarity analysis of 1264 plant protein kinase sequences (Hrabak et al., 2003).

All members of the CDPK/SnRK superfamily have kinase domains of similar length and sequence, and all have a similar general organization, with the kinase domains at or near the N-terminus, junction domains followed by the regulatory domains (Fig. 1). The major distinguishing features of the nine subfamilies are the primary structures of the terminal domains and the mode of kinase regulation (Harmon, 2003).

Five CDPK/SnRK subfamilies (CDPK, CCaMK, CaMK, CRK and SnRK3) are known to be regulated (or potentially regulated) directly or indirectly by calcium ions. Two subfamilies (CDPK and CCaMK)

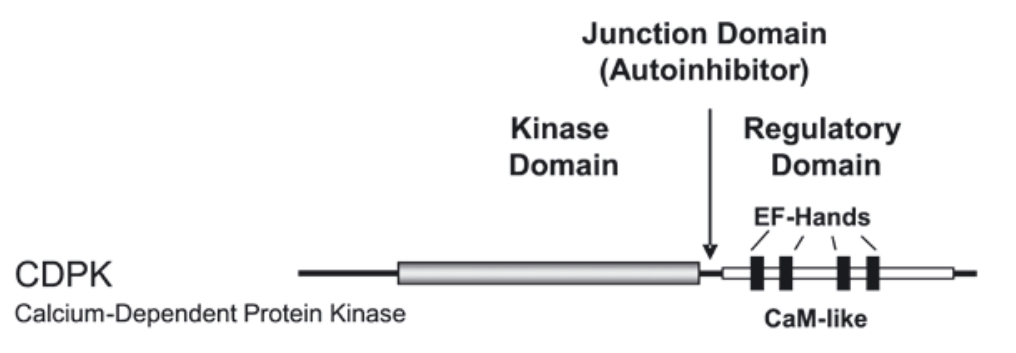

CRK

CDPK-related Kinase

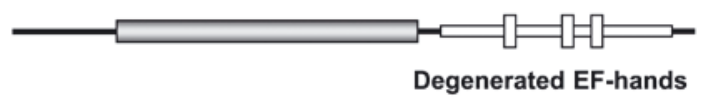

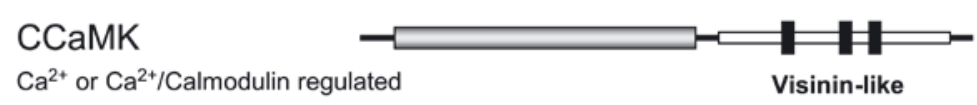

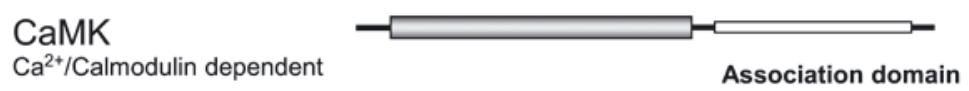

SnRK3

SNF1-related Kinase, type 3

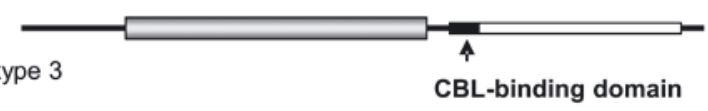

Figure 1. Diagram of kinase structures for members of the CDPK-SnRK superfamily.

Black boxes within the regulatory domain - functional EF-hands; white boxes within the regulatory domain - non-functional EF-hands; (adapted from Harmon, 2003; Harper et al., 2004) 
contain EF-hands at their C-terminal domains, three subfamilies (CCaMK, CaMK and CRK) bind calmodulin, and one subfamily (SnRK3) binds calcineurin B-like proteins (CBL).

CDPKs subfamily - CDPKs (calcium-dependent protein kinases) are monomeric proteins, with a molecular mass of 40 to $90 \mathrm{kDa}$. CDPKs consist of five domains, an amino-terminal variable domain, kinase domain, autoinhibitory domain, regulatory domain (CaM-LD - calmodulin-like domain) and a C-terminal domain of variable length (Harmon, 2003). CDPKs are unique owing to the presence of CaM-LDs that are able to couple the calcium sensor directly to its responder (kinase). This group of kinases was first discovered in plants. While structurally analogous kinases have been found in alveolates, the major line of protists, CDPKs have not been found in members of other phylogenetic branches, including fungi, insects, and mammals (Sanders et al., 2002).

CRKs subfamily - CRKs (CDPK-related kinases) have the same general structure as the CDPKs, but they have an apparently degenerated calmodulin-like domain. Of the eight Arabidopsis CRKs, three $(3,5$ and 8$)$ are predicted to have a pair of EF-hands but it is still not known if they are functional (Harmon, 2003).

CCaMKs subfamily - CCaMKs (calcium or calcium/calmodulin regulated kinases) have the same general structure as CDPKs, but they have calcium-binding domains with three EF-hands and they resemble the calcium-binding brain protein visinin rather than calmodulin. These enzymes are expressed in tobacco and lilly, but genes encoding CCaMK have not been found in Arabidopsis (Harmon et al., 2001). CCaMKs bind not only calcium but also calmodulin. The calmodulin-binding site is located at the C-terminal side of the autoinhibitory domain (Ramachandiran et al., 1997).

CaMKs subfamily - CaMKs (calmodulindependent protein kinases) are prevalent in animals; the only example of a putative plant CaMK is from apple (Watillon et al., 1993). Like in the case of CCaMKs, Arabidopsis does not have a gene for CaMK. These kinases are about 100 aa shorter than CCaMK and do not have any EF-hands (Harmon et al., 2001). Recombinant apple CaMK was shown to bind calmodulin, but the effect of calcium/calmodulin on the enzyme activity was not determined (Watillon et al., 1993).

SnRK3s subfamily - The SnRK3s (SNF1-related kinases, type 3), also called CIPKs (calcineurin B-like interacting protein kinase) or PKS (protein kinases related to SOS2), consist of a catalytic, autoinhibitory and C-terminal domains. Arabidopsis contains 25 SnRK3s, and many have been shown to interact with one of ten members of a family of EF- hands proteins called CBLs or SCaBP (calcineurin B-like/SOS3-like calcium binding proteins). The carboxy-terminal domain of the SnRK3s has no similarity to other members of the CDPK/SnRK family.

The CDPK/SnRK superfamily includes also four subfamilies (PPCK, PEPRK, SnRK1 and SnRK2) which are either known, or are predicted, not to be regulated by calcium ions (Harmon, 2003).

\section{CDPKS}

\section{Structure and isoforms}

Among the five domains of CDPKs, the $\mathrm{N}$ - and C-terminal ones are variable. The $\mathrm{N}$-terminal domains of CDPKs vary in length from 40 to 180 amino acids, and there is no high homology in the sequence between family members (Harmon, 2003). While none of the CDPKs appear to be integral membrane proteins, a significant percentage of CDPKs have potential myristoylation sites at the beginning of their highly variable $\mathrm{N}$-terminal domains. Myristoylation and palmitoylation at the N-terminus have been implicated in CDPK-membrane associations. Additionally, the PEST sequence has been localized at the N-terminus of some CDPKs (the PEST sequence is a proline, glutamine, serine and treoninerich region which was found in proteins undergoing rapid proteolytic degradation). The conserved kinase domain is typical for serine/threonine kinases, and the activation loop (between subdomains VII and VIII) contains acidic residues which make it unnecessary for the loop to be phosphorylated in order to activate the kinases. Adjacent to the catalytical domain is an autoinhibitory domain that contains a pseudosubstrate sequence that can interact with the active site and inhibit the activity. The last well conserved domain is the regulatory domain (calmodulin-like domain) which contains four EF-hands and is able to bind four moles of calcium per mole of enzyme. A relatively short C-domain follows the regulatory domain.

CDPKs are encoded by multigene families, for example in Arabidopsis thaliana there are 34 genes for CDPKs. A genome-wide analysis of Arabidopsis CDPKs provides an over-view of the diversity of this large multigene family and shows that gene duplication and subsequent divergence generated CDPKs with distinct functions. Information available from genomic sequencing as well as from expressed sequence tag (EST) projects, indicates the presence of multigene families of CDPKs in other plants, including soybean (Glycine max), tomato (Lycopersicon esculentum), rice (Oryza sativa), and maize (Zea mays) (Cheng et al., 2002). The relatively well known three CDPK isoforms $(\alpha, \beta, \gamma)$ from soybean differ from 
each other in their RNA expression patterns and biochemical and kinetic properties, including calcium binding properties. This supports the hypothesis that CDPKs, in spite of being members of a single family, play distinct roles in mediating various responses to $\mathrm{Ca}^{2+}$ signals (Lee et al., 1998).

\section{Substrate specificity}

A growing list of potential CDPKs substrates supports the view that conventional CDPKs are involved in the regulation of diverse cellular functions. In early studies two phosphorylation motifs named Simple 1 and 2 were revealed (Roberts \& Harmon, 1992; Neumann et al., 1996). Further analysis of peptide substrates has led to the recognition of four distinct motifs which define substrate specificity determinants outside the classic motifs (Table 1).

\section{Regulation of CDPK activity}

Regulation by calcium ions

The first and most important regulator of CDPKs activity are calcium ions. Due to the variation in the number and amino-acid sequence of the EF-hand motifs, CDPKs may differ in their affinity for $\mathrm{Ca}^{2+}$. For example, soybean isoforms $\alpha$ and $\gamma$ display $\mathrm{Ca}^{2+}$ activation thresholds that differ by more than ten-fold (isoform $\alpha$ shows a very low threshold around $60 \mathrm{nM}$ calcium). Thus, a low-magnitude $\mathrm{Ca}^{2+}$ spike may selectively activate $\operatorname{CDPK} \alpha$, and a much higher magnitude spike would activate both isoforms (Lee et al., 1998).

Presently two models of activation of CDPK by calcium exist, as illustrated in Fig. 2. In the first, CaM-LD (calmodulin like-domain) which is com- posed of two globular EF structural domains (Nlobe, C-lobe), each containing a pair of $\mathrm{Ca}^{2+}$ binding sites, is joined by a flexible tether to the kinase domain (Christodoulou et al., 2004). Upon stimulation by calcium ions, CaM-LD binds to the junction domain and displaces the autoinhibitor (model I). In the second model (model II), which is supported by current evidences, CaM-LD is pre-bound to the junction at basal levels of calcium ions (Harper et al., 2004). It has been suggested that under in vivo basal calcium ion concentrations, the C-terminal lobe is loaded with $\mathrm{Ca}^{2+}$ and is pre-bound to the junction domain. This implies that activation occurs through $\mathrm{Ca}^{2+}$ binding to the N-terminal lobe of CaM-LD. Consistent with this prediction, the Nterminal lobe displays a $K_{d}$ for calcium ions around $1 \mu \mathrm{M}$, as expected for a kinase regulated by typical cytosolic $\mathrm{Ca}^{2+}$ signals. The conformation of the $\mathrm{N}$-terminal lobe presumably changes in response to $\mathrm{Ca}^{2+}$ binding and somehow induces a conformational change in the autoinhibitory/kinase interaction.

Regulation by reversible phosphorylation

Apart from calcium ions, reversible phosphorylation and/or autophosphorylation may also regulate CDPK activity (Cheng et al., 2002). Phospho-regulation has been observed in the case of NtCDPK2. Phosphorylation of NtCDPK2 by an upstream kinase results in a 10- to 200-fold increase in maximum $\mathrm{Ca}^{2+}$-stimulated activity (Romeis et al., 2000; 2001). This phospho-activation occurs in response to certain pathogens, possibly through MAPK (mitogen-activated protein kinase) cascades. However, the upstream kinase and the site of phospho-regulation have not been determined (Harper et al., 2004).

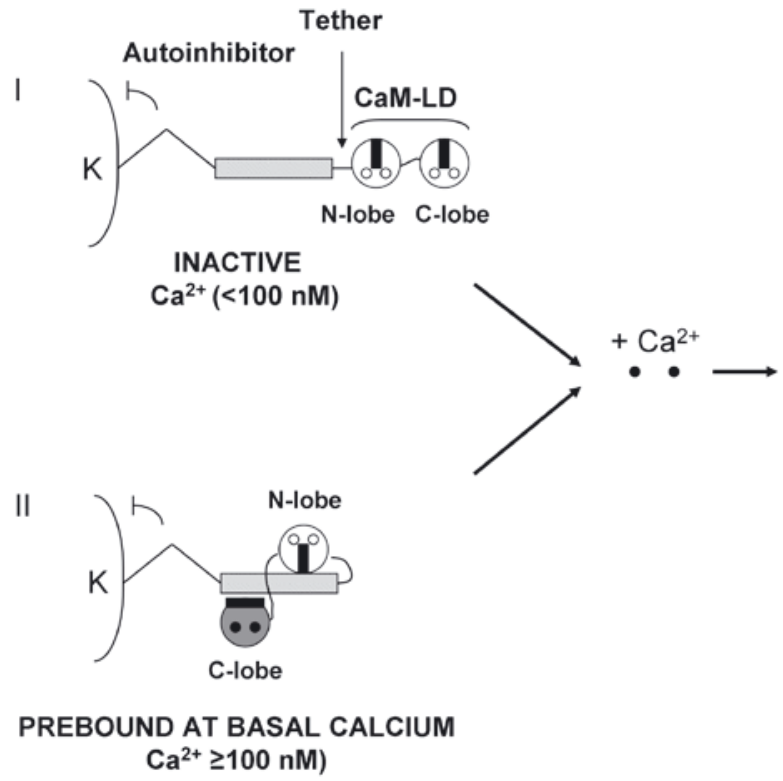

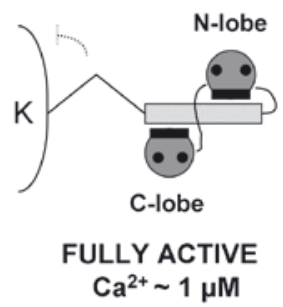
CDPKs.

$\mathrm{K}$, kinase domain; CaM-LD, calmodulin-like domain; white dots within $\mathrm{N}$ - and C-lobes, empty $\mathrm{Ca}^{2+}$ binding sites; black dots within $\mathrm{N}$ - and C-lobes, $\mathrm{Ca}^{2+}$ binding sites with bound $\mathrm{Ca}^{2+}$ (modified from Harper et al., 2004; Harper \& Harmon, 2005). 
Autophosphorylation has been observed in both native and recombinant CDPKs. Although phosphorylation sites in many CDPKs have been defined, still little is known about the effects of autophosphorylation on CDPK function in vitro, and almost nothing is known about its physiological or mechanistic role in vivo (Hegeman et al., 2006). For example, in vitro autophosphorylation is prerequisite for activation of a ground nut (Arachis hypogea) AhCDPK (Chaudhuri et al., 1999), but contrary to that it can also cause inhibition of the WbCDPK activity, which was observed in the winged bean (Psophocarpus tetragonologus). In addition to that, a soluble phospho-Ser phosphatase from winged bean shoots activates in vitro (by dephosphorylation) autophosphorylated WbCDPK (Ganguly \& Singh, 1999). It is thought that this action reverses the inhibitory effect of autophosphorylation.

In almost all studied cases autophosphorylation is $\mathrm{Ca}^{2+}$-dependent. An interesting exception is WbCDPK, the autokinase activity of which is apparently calcium-independent (Saha \& Singh, 1995). Also interesting is that a second isoform of CDPK from that organism, designated $\mathrm{WbPK}$ (winged bean protein kinase), is the only reported example of a CDPK that does not exhibit an autokinase activity (Ganguly \& Singh, 1998).

Regulation by phospholipids

Biochemical analysis has revealed that in the presence of calcium ions also certain phospholip- ids can enhance in vitro protein phosphorylation by CDPKs from oat (Avena sativa) (Schaller et al., 1992), Arabidopsis (AtCPK1) (Harper et al., 1993), carrot (Daucus carota, DcCPK1) (Farmer \& Choi, 1999) and maize (Zea mays, ZmCPK11) (Szczegielniak et al., 2000; 2005). The stimulation of CDPK activity by membrane lipids suggests that membrane association may be a factor that contributes to CDPK activity. Furthermore, as can be seen in Table 2 the phospholipids regulating the kinase activities are different for different CDPKs. Because of the differential specificity of the phospholipids stimulating each CDPK, the effects will likely have physiological relevance. There is evidence that some of these phospholipids do act as second messengers in plant signal transduction, and, therefore, might elicit their effects through CDPKs (Cheng et al., 2002).

Regulation by 14-3-3 proteins

Data accumulating during the recent decade has indicated that phosphorylation alone is not always sufficient to complete the transduction of a regulatory signal. In many cases, the phosphorylated target protein must associate with a specialized adapter protein. The most known adapter protein is 14-3-3, which is able to complete the regulatory action of phosphorylation. The 14-3-3 protein was first identified as a brain protein, now it is known that it is ubiquitous in all eukaryotes (Moorhead et al., 1999).

\section{Table 1. Motifs phosphorylated by CDPKs.}

Subscripts denote the position of residues relative to the phosphorylation site, which is bold residues (S or $\mathrm{S} / \mathrm{T}$ ). Basic - R or K; X - any residue; Z - any residue except R; $\phi$ - hydrophobic residue (Harper \& Harmon, 2005, modified).

\begin{tabular}{|c|c|c|}
\hline Motif & Sequence & Reference \\
\hline Simple 1 & Basic $_{-3}-\mathrm{X}_{-2}-\mathrm{X}_{-1}-\mathrm{S} / \mathrm{T}_{0}$ & Roberts \& Harmon, 1992 \\
\hline Simple 2 & $\mathrm{~S}_{0}-\mathrm{X}_{+1}-\mathrm{Basic}_{+2}$ & Neumann et al., 1996 \\
\hline $\begin{array}{l}\text { Motif } 1 \\
\text { minimal } \\
\text { optimal }\end{array}$ & $\begin{array}{l}\phi_{-5}-\mathrm{X}_{-4}-\mathrm{Basic}_{-3}-\mathrm{X}_{-2}-\mathrm{X}_{-1}-\mathrm{S}_{0}-\mathrm{X}_{++1}-\mathrm{X}_{+2}-\mathrm{X}_{+3}-\phi_{+4} \\
\text { Basic }-6 \phi_{-5}-\mathrm{X}_{-4}-\text { Basic }_{-3}-\mathrm{X}_{-2}-\mathrm{X}_{-1}-\mathrm{S}_{0}-\mathrm{X}_{+1}-\mathrm{X}_{+2}-\mathrm{X}_{+3}-\phi_{+4}-\text { Basic }_{+5}\end{array}$ & $\begin{array}{l}\text { Neumann et al., } 1996 \\
\text { Huang \& Huber } 2001\end{array}$ \\
\hline Motif 2 & Basic $_{-9}-$ Basic $_{-8}-\mathrm{X}_{-7}-$ Basic $_{-6}-\phi_{-5}-\mathrm{X}_{-4}-\mathrm{X}_{-3}-\mathrm{X}_{-2}-\mathrm{X}_{-1}-\mathrm{S}_{\mathbf{T}}-\mathrm{T}_{0}-\mathrm{X}_{+1}$ Basic $_{+2}$ & $\begin{array}{l}\text { Huang et al., 2001; Huang \& Huber, } \\
2001\end{array}$ \\
\hline Motif 3 & $\phi_{-1}-\mathrm{S} / \mathbf{T}_{0}-\phi_{+1}-\mathrm{X}_{+2}-$ Basic $_{+3}-$ Basic $_{+4}$ & Sebastià et al., 2004 \\
\hline Motif 4 & $\mathrm{~A} / \mathrm{L}_{-5}-\mathrm{X}_{-4}-\mathrm{R}_{-3}-\mathrm{X}_{-2}-\mathrm{X}_{-1}-\mathrm{S}_{0}-\mathrm{X}_{+1}-\mathrm{R}_{+2}-\mathrm{Z}_{+3}-\mathrm{R}_{+4}$ & Loog et al., 2000 \\
\hline
\end{tabular}

Table 2. Efect of different phospholipids on activity of CDPK.

AtCDPK1, Arabidopsis thaliana (Harper et al., 1993); DcCPK1, Daucus carota (Farmer \& Choi, 1999); ZmCPK11, Zea mays (Szczegielniak et al., 2005); CDPK, Avena sativa (Schaller et al., 1992).

\begin{tabular}{llllllll}
\hline CDPK & PA & PS & PI & PC & LysoPC & PE & $\begin{array}{l}\text { Crude } \\
\text { extract }\end{array}$ \\
\hline AtCPK1 & 0 & 0 & ++ & 0 & ++ & 0 & + \\
DcCPK1 & ++ & + & + & n.d. & 0 & & ++ \\
ZmCPK11 & ++ & ++ & + & 0 & 0 & n.d. & + \\
Oat CDPK & n.d. & + & + & + & + & n.d. & ++ \\
\hline
\end{tabular}

n.d., not determined; 0 , no effect; "+", stimulation of activity; “++", strong stimulation of activity; Crude extract, mixture of lipids isolated from particular plant homogenate; PA, PS, PI, PC, LysoPC, PE, commercial phospholipids. 
In plants there are many isoforms of 14-3-3 proteins, for example 12 isoforms in Arabidopsis (Sehnke et al., 2002). Three different 14-3-3 isoforms have been demonstrated to specifically bind and activate AtCPK1 in vitro in the presence of calcium ions. There was no stimulatory effect of 14-3-3 in the absence of calcium ions. Thus, 14-3-3 does not merely mimic $\mathrm{Ca}^{2+}$ but rather provides an additional stimulation once the enzyme is activated (Camoni et al., 1998). Calcium ions may be needed in part to induce autophosphorylation of CDPK, because 14-3-3 proteins typically regulate the activities of many enzymes by binding to specific phosphorylated residues. Although the specific sites of AtCPK1 autophosphorylation and its interaction with 14-3-3 are unknown, AtCPK1 contains one site within the $\mathrm{N}$-terminus similar to the most common 14-3-3 consensus binding site, R-S/T-X-S-X-P, where the underlined Ser is phosphorylated. Such putative 14-3-3 binding sites are also present in two other Arabidopsis CDPKs, AtCPK24 and AtCPK28 (Cheng et al., 2002).

\section{Subcellular localization and organ expression of CDPKs}

In plants, CDPKs are present as both soluble and membrane-anchored isoforms. CDPKs exhibit multiple locations, including the cytosol, nucleus, plasma membrane, endoplasmatic reticulum, peroxisomes, mitochondrial outer membrane and oil bodies (Harper et al., 2004). In A. thaliana, 9 of 34 isoforms have been localized either in the nucleus, cytoplasm, or associated with the plasma membrane (Lu \& Hrabak, 2002; Dammann et al., 2003). In Nicotiana tabacum, NtRpn3, a regulatory subunit of $26 \mathrm{~S}$ proteasome, was identified as protein interacting with NtCDPK1. Both proteins are co-localized in the nucleus, nucleus periphery, and around the plasma membrane (Lee et al., 2003). The $26 \mathrm{~S}$ proteasome represents the first example of a specific protein complex containing CDPK (Harper et al., 2004).

In addition to the diverse subcellular distribution of CDPKs, there is evidence that some of them can change locations in response to stress. Such a situation was observed in the ice plant (Mesembryanthemum crystallinum), where expressed in leaves isoform of McCPK1 tagged with green fluorescent protein (GFP) showed a pronounced shift in localization from the plasma membrane to the nucleus in response to a salt or dehydratation stresses (Patharkar \& Cushman, 2000; 2006).

Transcripts of CDPKs have been found in every studied plant and plant organ. In many cases CDPKs are strongly expressed in proliferating tissues. In $N$. tabacum NtCDPK1 is mainly expressed in the rapidly proliferating tissues including shoot and root meristems and developing flower buds. Another tobacco CDPK (NtCPK4) is expressed additionally in rapidly growing tissues such as root tip, lateral root primodia, vasculature in leaf and anther, suggesting that it might be related to cell differentiation and particular metabolic function (Lee et al., 2003; Zhang et al., 2005). The highest level of expression of cytosolic OsCDPK13 from rice was also detected in young tissues (Abbasi et al., 2004). The highest transcript level of maize CDPK, ZmCPK11, was observed in seedlings, also rapidly growing tissues (Szczegielniak et al., 2005). Transcripts of CDPKs have been detected in seeds and pollen. Rice CDPK (SPK) is expressed uniquely in the endosperm of immature seed (Asano et al., 2002). The expression of one of maize CDPK genes is pollen-specific and is temporally restricted to the late stages of pollen development (Estruch et al., 1994).

Plant organs grown in the light or in darkness exhibit different expression and activity of some CDPKs. The presence of varying levels of CpCPK1 activity among different organs of light- and darkgrown roots, hypocotyls, hooks, and cotyledons of zucchini (Cucurbita pepo L.) was demonstrated. The level of $C P C P K 1$ mRNA isolated from zucchini seedlings was higher in dark-grown than in their lightgrown counterparts. In dark-grown tissue, expression was the highest in the hypocotyls followed by hooks and roots, whereas little or no expression was detected in dark-grown cotyledons. In light-grown tissue, expression was greatly reduced (Ellard-Ivey et al., 1999). Significant differences between etiolated and light-grown tissues was observed also in apple (Malus domestica Borkh. cv. Braeburn) and maize. A detailed study in both light-grown and etiolated maize plants revealed that expanding tissues, such as rapidly growing tips, leaves, and coleoptiles had particularly high levels of p67CDPK activity. Mature etiolated leaves had less activity, but it was still higher than in mature light-grown leaves. An inactivating effect of light was confirmed where p67CDPK activity dropped in etiolated secondary leaves after $8 \mathrm{~h}$ of their exposure to light (Barker et al., 1998). Exposure to light was found to differentially regulate the transcript level of CsCDPK3 isolated from various organs of cucumber (Cucumis sativus). The transcript level decreased in light-grown hypocotyls and roots, whereas in cotyledons light had an up-regulatory effect (Ullanat \& Javabaskaran, 2002). This means that light-regulated transcription of CDPKs is organ-specific. In maize, the transcript levels of $\mathrm{Zm}$ $C D P K 7$ and ZmCDPK9 were higher in etiolated than in light-grown leaves (Saijo et al., 1997). In rice plants overexpressing OsCDPK2, in etiolated leaves, stems and flowers the higher level of the transcript was detected (Morello et al., 2000). Also in wheat seedlings (Sharma et al., 1997), and in seedlings of the 
short-day plant Pharbitis nil (Jaworski et al., 2003), activity of CDPKs was higher in etiolated tissues.

\section{Putative functions of CDPKs}

The CDPK superfamily members, as expected for a family of multifunctional kinases with many substrates, have been implicated in many biological phenomena (Table 3) (Harper \& Harmon, 2005).

In vitro phosphorylation reactions make it possible to identify potential CDPK protein substrates involved in carbon and nitrogen metabolism, phospholipid synthesis, defense responses, ion and water transport, cytoskeleton organization, transcription, fertilization and proteasome regulation (Reddy \& Reddy, 2004). For example, the phosphorylation by CDPK of enzymes that are involved in carbon and nitrogen metabolism might coordinate the supply of carbon skeletons and ammonia needed for synthesis of carbon stores or amino acids (Huber \& Hardin, 2004). Consistent with this, the accumulation of starch was disrupted in rice seeds by antisense knockdown of an endosperm-specific CDPK
(Asano et al., 2002). Phosphorylation by CDPKs of such enzymes as phenylalanine ammonia lyase and 3-hydroxy-3-methylglutaryl-CoA reductase might stimulate the production of defense compounds in response to pathogen attack, or the regulation of membrane-associated ion and water transporters, which might alter signal transduction, transport of nutrients and turgor (Harmon et al., 2000). Another example is phosphorylation of ACC synthase, which catalyses the rate-determining step in the biosynthesis of ethylene, a gaseous hormone that is produced in response to developmental signals and various stresses (Sebastià et al., 2004).

Role in rearrangements of cytoskeleton organization

Dynamic cytoskeleton reorganization is essential for a variety of cell functions, mainly proliferation and differentiation. The actin cytoskeleton in eukaryotic cells forms a dynamic network that can reorganize in response to intracellular and extracellular signals. These reorganizations are coordinated by stimulus-responsive actin-modulating proteins. To this group belong profilins and actin-depolym-

Table 3. Known potential CDPKs substrates.

Substrates were identified through in vitro phosphorylation and are grouped according to their biological functions (Cheng et al., 2002; Reddy \& Reddy, 2004; modified).

\begin{tabular}{|c|c|c|}
\hline Putative substrates & CDPK source & References \\
\hline \multicolumn{3}{|l|}{ Carbon metabolism } \\
\hline Sucrose phosphate synthase & Spinach & McMichael et al., 1995a, b \\
\hline Sucrose synthase & Soybean & Nakai et al., 199; Zhang \& Chollet, 1997 \\
\hline Phosphoenolpyruvate carboxylase & Maize and soybean & Ogawa et al., 1998 \\
\hline \multicolumn{3}{|l|}{ Nitrogen metabolism } \\
\hline Nitrate reductase & Spinach & Douglas et al., 1998; McMichael et al., 1995a \\
\hline \multicolumn{3}{|l|}{ Phospholipid metabolism } \\
\hline PI 4-kinase activator & Carrot & Yang \& Boss, 1994 \\
\hline \multicolumn{3}{|l|}{ Ethylene synthesis } \\
\hline ACC synthase & Maize & Sebastià et al., 2004 \\
\hline \multicolumn{3}{|l|}{ Defense response } \\
\hline Components in Cf9/Avr9-induced HR & Tobacco & Romeis et al., 2001 \\
\hline Phenylalanine ammonia lyase & French bean & Cheng et al., 2001 \\
\hline \multicolumn{3}{|l|}{ Ion and water transport } \\
\hline Aquaporins & Spinach & Huang et al., 2001 \\
\hline Plasma membrane $\mathrm{H}^{+}$-ATPase & Oat and maize & Camoni et al., 1998; Harmon et al., 1996 \\
\hline Potassium channel KAT1 & Broad bean & Li et al., 1998; Berkowitz et al., 2000 \\
\hline $\mathrm{Ca}^{2+}$-ATPase (ACA2) & Arabidopsis & Hwang et al., 2000 \\
\hline \multicolumn{3}{|l|}{ Cytoskeleton organization } \\
\hline Actin-depolymerizing factor & French bean & Allwood et al., 2001 \\
\hline \multicolumn{3}{|l|}{ Transcription } \\
\hline Pseudoresponse regulator & Ice plant & Patharkar \& Cushman, 2000 \\
\hline \multicolumn{3}{|l|}{ Proteasome regulation } \\
\hline $26 \mathrm{~S}$ proteasome regulatory factor & Tobacco & Lee et al., 2003 \\
\hline \multicolumn{3}{|l|}{ Fertilization regulation } \\
\hline Self-incompability RNases & Tobacco & Kuntz et al., 1996 \\
\hline \multicolumn{3}{|l|}{ RNase activity } \\
\hline Ser acetyltransferase & Soybean & Harmon, 2003 \\
\hline
\end{tabular}


erizing factor (ADF). It was known earlier that the reversibly phosphorylated vertebrate ADF does not bind G- and F-actin and is consequently inactive in in vitro polymerization/depolymerization assays. Studies of Smertenko and co-workers (1998) on actin depolymerization in maize revealed that the maize actin-depolymerizing factor (ZmADF3) can be phosphorylated on Ser- 6 by a protein kinase in a $\mathrm{Ca}^{2+}$-dependent manner. An analogue of phosphorylated ZmADF3, in which Ser-6 was replaced by a negatively charged residue (aspartate) did not bind G- or F-actin and had a negligible effect on the rate of disassembly of actin. This means that reversible phosphorylation of Ser-6 controls the functioning activity of actin. Results of another group working on regulation of actin tension in soybean cells confirmed that phosphorylation may be necessary for maintenance of F-actin interactions with either myosin filaments or actin-binding proteins (Grabski et al., 1998).

Role in growth, development and differentiation

A wide variety of growth and developmental processes in plants are regulated by $\mathrm{Ca}^{2+}$ fluxes (Hepler et al., 2001). It has been shown that abiotic stresses such as oxidative and hypoosmotic stress increase the cytoplasmic $\mathrm{Ca}^{2+}$ level in synchronized BY-2 cells, which in turn causes a delay of cell cycle progression (Sano et al., 2006). The environmental stimuli and signaling events that trigger and regulate plant embryogenesis are largely unknown, however, studies carried out on a carrot system have shown that $\mathrm{Ca}^{2+}$ enhances embryogenetic frequency and its deprivation arrests somatic embryo formation. In addition, the accumulation of a 55-kDa soluble calcium dependent protein kinase (swCDPK) has been observed only in somatic/zygotic embryos, endosperm and seedlings of sandalwood (Santalum album). The developmentally regulated, tissue-specific expression of this CDPK isoform suggests its involvement in early developmental processes such as embryogenesis, seed development and germination (Anil \& Rao, 2000; 2001).

The exclusive expression of a CDPK named SPK in the endosperm of immature rice seeds suggested its involvement in biosynthetic pathways of storage products (Asano et al., 2002). This hypothesis was confirmed by a study of antisense SPK transformants, which lacked the ability to accumulate storage products such as starch and produced watery seed with a large amount of sucrose instead, as a result of an inhibition of sucrose utilization. This finding suggests that SPK is a sucrose synthase kinase that may be important for supplying substrates for the biosynthesis of storage products.
Germination and growth of the pollen tube require intense cytoplasmic streaming and cytoskeleton reorganization. Because these processes are thought to be $\mathrm{Ca}^{2+}$-dependent the pollen-specific maize CDPK protein may serve a very specific function during germination and growth of the pollen tube by acting as a stimulus-response protein (Estruch et al., 1994). This hypothesis was confirmed by a study of cells of pollen tubes of Agapanthus umbellatus. It was found that the pollen tubes exhibited a higher protein kinase activity in the apical region, whereas nongrowing cells showed uniform distribution of the kinase activity (Moutinho et al., 1998).

Tuberization is a complex process that results in differentiation of specialized shoot (the stolon) into a storage organ (the tuber). A wide variety of environmental and hormonal stimuli are known to be involved in the induction of tuberization (MacIntosh et al., 1996). Also, intracellular $\mathrm{Ca}^{2+}$ is necessary for tuber development and calmodulin antagonists can inhibit this process. Participation of CDPK isoforms in tuber development was studied during potato (Solanum tuberosum L.) tuber formation. Two CDPK activities (StCDPK1 and StCDPK3) with different substrate specificity and cellular distribution were found associated with early (thin) or induced (swelling) stolons. Differential expression of StCDPK3 (only transcribed in early elongating stolons) and StCDPK1 (expressed upon swelling of the stolon tip) confirmed the existence of specific CDPK isoforms with restricted patterns of expression and activity during the events leading to tuber formation. This data suggest that sequential activation of specific CDPKs with distinct biochemical properties and subcellular localization could be essential for the co-ordination of multiple $\mathrm{Ca}^{2+}$ signals triggered upon tuberization (Raices et al., 2003).

Role in regulation of transcription

In contrast to yeast and animals, little is known about the regulation of plant transcription factors by reversible phosphorylation. It has been demonstrated that in wheat, a bZIP (basic/leucinezipper motif) transcription factor (named HBP-1a) can be phosphorylated at three Ser residues: 261, 265 and 269 in a $\mathrm{Ca}^{2+}$-dependent manner by a kinase present in the nuclear extract (Meshi et al., 1998). DNA-binding analysis of mutants in which Ser was substituted by Glu indicated that the phosphorylation of residues 265 and 269 prevents HBP-1a from binding DNA. This suggests that the phosphorylation regulates the function of HBP-1a at the level of DNA binding at least (Meshi, 1998).

The regulation of trans-acting factors by reversible phosphorylation could be a key post-translational modification responsible for stability, migration from the cytosol to the nucleus, oligomeriza- 
tion of the factors themselves, and for interactions with proteins of the transcriptional machinery. $\mathrm{Ca}^{2+}$-dependent phosphorylation is responsible for modulation of the DNA-binding activity of GT-1, a trans-acting factor (Maréchal et al., 1999). GT-1 is a light-modulated DNA-binding protein interacting with BoxII in vitro in $r b c S-3 A$ promoter in pea plants. Analysis of recombinant GT-1 mutants has demonstrated that phosphorylation of Thr-133 is accountable for a 10-20-fold stimulation of DNA-binding activity. Treatment with calf intestine alkaline phosphatase of extracts prepared from light-grown plants (but not from etiolated ones) reduced the GT1 DNA-binding activity, suggesting that GT-1 may act as a molecular switch modulated by $\mathrm{Ca}^{2+}$-dependent phosphorylation and dephosphorylation in response to light signals.

It has been shown that cold shock causes an increase in cytosolic free calcium ion concentration in A. thaliana (Knight et al., 1996; Knight \& Knight, 2000). Inhibition of this increase causes a partial inhibition of kin1 (cold-induced gene) expression, which in connection with kin2 expression is probably important for cold acclimation of plants. W7, an antagonist of CDPKs and calmodulin, not only decreased the cold-induced expression of kin genes but also prevented the cold acclimation of Arabidopsis plants. These results suggest that CDPKs may couple the $\mathrm{Ca}^{2+}$ response to downstream events, leading to metabolic adjustment to the cold and to the development of freezing tolerance (Tähtiharju et al., 1997). The involvement of calcium ions in the regulation of plastid-encoded photosynthesis-related genes ( $p s b A$, $p s a A$, and $r b c L$ ) in rice leaves was studied by Grover and co-workers. The observed significant decrease in the transcript level of $p s b A, p s a A$ and $r b c L$ in response to calcium ion channel blockers (nifedipine and verapamil) and protein phosphatase inhibitors (okadaic acid and sodium fluoride) may suggest that phosphorylation/dephosphorylation plays a role during biogenesis of leaves chloroplasts (Grover et al., 1998).

Role in hormone responses

CDPKs are known to modulate $\mathrm{Ca}^{2+}$-dependent plant responses caused by phytohormones, mostly gibberellins, cytokinins and auxins. One of the first documented examples of gibberellin influence on the activity of CDPK was observed in gibberellin-treated rice seeds. The activity of partly purified rice CDPK was 10-fold higher in GA-treated seeds than in untreated ones (Abo-El-Saad \& Wu, 1995). Additionally, GA treatment caused an increase of the transcript level of another CDPK from rice seedlings, OsCDPK13 (Yang et al., 2003). In tobacco, accumulation of NtCPK4 transcript was also observed after GA treatment, reaching a maximum after $60 \mathrm{~min}$ and returning to the initial level during the next $2 \mathrm{~h}$ (Zhang et al., 2005). An influence of GA was observed in aleurone cells of barley (Hordeum vulgare) expressing an inactivated (D140N) version of HvCDPK1. Secretion, cell vacuolation, and vacuolar acidification were inhibited, while GA-induced gene expression was not affected by the inactive version of HvCDPK1. Therefore, HvCDPK1 may play a role in regulating post-transcriptional events in protein secretion (McCubbin et al., 2004). A different regulation by plant hormones was observed in rice roots, where the activity of a $45 \mathrm{kDa} C D P K$ decreased previously by cold was recovered by exogenous abscisic acid (ABA). This may suggest that the $45 \mathrm{kDa}$ protein kinase activity regulated by $\mathrm{ABA}$ is involved in the cold-stress response in rice (Komatsu et al., 2001). Studies of ACPK1 from the mesocarp of grape barriers (Vitis vinifera $x$ V. labrusca) revealed that ABA stimulates both the activity of the kinase and mRNA level, but not at the same time. The rapid stimulation of the ACPK1 activity after $15 \mathrm{~min}$ of ABA treatment without an increase of the ACPK1 protein level suggests involvement of the enzyme in mediating some rapid ABA-responsive events (ABA could probably act on post-translational modification of ACPK1). A much slower de novo ABA-stimulated synthesis of ACPK1 implicates its role in regulating a development-related ABA-signaling pathway ( $\mathrm{Yu}$ et al., 2006). An influence of GA and ABA treatment was observed also in tobacco, where accumulation of NtCDPK1 mRNA occurred $12 \mathrm{~h}$ after treatment with the phytohormones (Yoon et al., 1999).

Auxins also influence the expression and activity of CDPKs. For example, in tobacco leaves treated with indole-3-acetic acid (IAA) a slight induction of NtCDPK1 transcript was observed (Yoon et al., 1999), while after the treatment of mung bean plants (Vigna radiata) a significant increase in the transcript level occurred, reaching a maximum $6 \mathrm{~h}$ after the treatment (Botella et al., 1996). Another example of CDPK transcript accumulation after auxin $(2,4 \mathrm{D})$ treatment was observed in microcallus suspension of alfalfa (Medicago sativa) during embryogenic induction. The maximal level of MsCPK3 transcript was observed after $2 \mathrm{~h}$ (Davletova et al., 2001). Activity of $50 \mathrm{kDa}$ CDPK was detected in extracts from cucumber hypocotyls after first day of IAA treatment and it was extended to the third day of continuous treatment. It has been suggested that, together with $\mathrm{NO}$, which also increases the activity of this CDPK, IAA plays a role in a $\mathrm{Ca}^{2+}$-mediated signaling pathway that regulates CDPK activity leading to adventitious root formation (Lanteri et al., 2006). Cytokinins affect the transcript level of CsCDPK3 from cucumber, and this effect differs between organs. Treatment with benzyladenine (a synthetic cytokinin) up-regulated the transcript level of this 
kinase in cotyledons in opposition to a down-regulatory effect in roots and a lack of a significant effect in hypocotyls (Ullanat \& Jayabaskaran, 2002). An interesting observation was made during studies on rice BRI1, a receptor of a group of brassinosteroids (BRs), and its influence on MAPK and CDPK activity. After exogenous application of brassinolide both MAPK and CDPK were activated. In control as well as in OsBRI1 antisense-expressing rice plants only an increase of CDPK (in contrast to MAPK) activity was observed. These results suggest that brassinosteroids cause activation of CDPK via a receptor different from BRI1 identified for MAPK activation (Sharma et al., 2001).

It is also known that $\mathrm{Ca}^{2+}$-dependent protein phosphorylation is involved in plant response triggered by the gaseous plant hormone ethylene which regulates a variety of physiological processes including fruit ripening, leaf abscission and senescence as well as response to environmental stresses such as wounding and pathogen invasion (Kwak \& Li, 1997; Ludwig et al., 2005).

Role in plant stress signal transduction and defense responses

In response to a particular stress, e.g. cold, drought, high salinity or wounding, plants exhibit recognizable cytoplasmic calcium ion elevations decoded by CDPKs (Knight \& Knight, 2001). Elevation in transcription level as well as an increase of the activity of CDPKs has been observed as a response to different stresses. In roots and shoots of 10-day-old rice seedlings, after cold or salt treatment the level of OsCDPK7 transcript was increased. Overexpression of OsCDPK7 made transgenic rice lines more tolerant to cold, drought and salt stress, therefore OsCDPK7 seems to play a role in the tolerance to different types of stresses in rice (Saijo et al., 2000). In tobacco leaves the NtCDPK1 gene is transcriptionally regulated not only by phytohormones (ABA, GA and cytokinin or methyl jasmonate) and $\mathrm{Ca}^{2+}$, but also by abiotic and biotic stimuli such as $\mathrm{NaCl}$, wounding, fungal elicitors and chitosan. The induction occurs quite rapidly; the level of NtCDPK1 mRNA increases after $1-2 \mathrm{~h}$ treatment with fungal elicitors, chitosan or $\mathrm{NaCl}$. However, the duration of the elevation of the mRNA level appeared to vary depending on the treatment (Yoon et al., 1999). Transcript of another tobacco CDPK, NtCPK4, was induced not only by a phytohormone (GA) but also by $\mathrm{NaCl}$ treatment. The maximal transcript level was observed 30 min after $\mathrm{NaCl}$ treatment and returned to basal level in $2 \mathrm{~h}$ (Zhang et al., 2005). Northern blot analysis of total RNA isolated from dehydrated Arabidopsis plants indicated that mRNAs corresponding to the AtCDPK1 and AtCDPK2 genes are rapidly induced by drought and high-salt stress but not by low temperature or heat stress. These findings suggest that a change in the osmotic potential of the environment can serve as a trigger for the induction of AtCDPK1 and AtCDPK2 (Urao et al., 1994). An increase in the activity of a $51 \mathrm{kDa}$ cytoplasmic CDPK was observed in rice plants treated with cold, salt or drought stresses (Li \& Komatsu, 2000). The activity of another CDPK from rice, a membrane-bound 56kDa CDPK, was increased by cold treatment (Martin \& Busconi, 2001). Cold treatment also caused an accumulation of OsCDPK13 transcript in 2-week-old rice plants (Abbasi et al., 2004). Not only cold, but also heat shock can affect CDPKs transcript level. Thirty minutes after heat shock $\left(37^{\circ} \mathrm{C}\right)$ an induction of expression of MsCPK3 from alfalfa was observed. This is a unique example of such induction, not observed in other plant species studied (Davletova et al., 2001).

NtCDPK1 from tobacco is a CDPK which is induced transiently during wounding (Ludwig et al., 2004). The NtCDPK1 transcript appeared within $2 \mathrm{~h}$, went down at $11 \mathrm{~h}$ and disappeared at $28 \mathrm{~h}$ after wounding (Yoon et al., 1999). An increase in the transcript level after mechanical strain treatment (manually bent downward) was also observed in leaves of 10-day-old mung bean plants, where induction of $\operatorname{VrCDPK} 1$ expression was observed 30 min after treatment reaching a maximum after 60 min and then remaining constant up to $3 \mathrm{~h}$ (Botella et al., 1996). In tomato plants subjected to mechanical wounding, a transient increase in the LeCDPK1 mRNA steady-state level was detected not only locally at the site of the injury, but also systemically in distant non-wounded leaves. Analysis of LeCDPK1 mRNA in whole plants subjected to wounding showed that the kinase expression in injured leaves reaches a maximum at $4 \mathrm{~h}$ whereas in neighboring leaflets or distal leaves its mRNA appeared later (after $8-12 \mathrm{~h}$ or $18 \mathrm{~h}$, respectively). The increase observed in LeCDPK1 mRNA upon wounding correlates with an increase in the amount and activity of a soluble CDPK detected in extracts of tomato leaves, suggesting that the kinase is a part of mechanisms involved in plant responses to abiotic stresses (Chico et al., 2002). Similar responses were also observed in maize, where wounding induced accumulation of the ZmCPK11 transcript in both wounded and neighboring leaves (after $3 \mathrm{~h}$ and $6 \mathrm{~h}$, respectively). These results indicate that monocot, alike dicot plants are able to respond to wounding in a systemic way (Szczegielniak et al., 2005).

Wounding commonly occurs as a result of abiotic stress factors such as wind, rain, and hail or is caused by phytopathogens and herbivores. Wounding presents a constant threat to plant survival because it not only physically destroys plant tissues, but also provides a pathway for pathogen 
invasion (Cheong et al., 2002). Because plants do not have specialized cells devoted to wound healing such as those found in mammals, some plant cells have evolved towards the capacity of making each cell competent for the activation of defense responses. These wound-activated responses are directed to healing of the damaged tissues and to the activation of mechanisms that prevent further damage (León et al., 2001). Such mechanisms largely depend on the transcriptional activation of wound-responsive (WR) genes. Several components involved in the transduction of wound signals have been identified, mostly in tomato. Oligosaccharides, the peptide systemin, the phytohormones: JA, ABA and ethylene together with electrical signals have been shown to play a role in the signaling network leading to the activation of proteinase inhibitors and other WR genes (Rojo et al., 1999). Elevation of intracellular levels of free calcium ions and changes in the pattern of phosphorylation catalysed by CDPKs are also parts of the wound-activated responses in plants.

Elicitor-induced calcium ion influx and changes of CDPKs activity and their transcript levels have been reported for many pathogen-plant interactions as one of the earliest responses required for further downstream signaling. Transcript accumulation of NtCDPK1 from tobacco was reported upon nonrace-specific elicitation with chitin fragments (Yoon et al., 1999). In tobacco cells that expressed the resistance gene from tomato $(C f-9)$ as a transgene, NtCDPK2 was activated upon elicitation with the corresponding fungal-derived avirulence gene product Avr9 (Romeis et al., 2000). Interest- ingly, the enzyme activation was accompanied by a phosphorylation-dependent transition of NtCDPK2 from a non-elicited into an elicited enzyme form, which could be visualized as a shift in electrophoretic mobility in immunoblot and in-gel kinase assays (Romeis et al., 2001). Another example of a CDPK involved in pathogen defense response is $\mathrm{ZmCPK10}$ from maize. This kinase is transcriptionally activated in response to both fungal infection (Fusarium moniliforme) and treatment with its elicitors. Activation of ZmCPK10 gene is extremely rapid, its transcript could be detected $5 \mathrm{~min}$ after elicitation and reached maximum levels $30 \mathrm{~min}$ after treatment. The activation of this kinase gene is accompanied by an increase in the level of PR transcripts. The PRs are the pathogenesis-related proteins whose expression is induced in tissues in response to fungal infection and treatment with fungal elicitors. Interestingly, the notable cell-typespecific pattern of ZmCPK10 gene expression fully correlates with the pattern of PR gene expression in both fungus-infected and elicitor-treated maize tissues (Murillo et al., 2001).

Participation of CDPKs in cross-talk between signal transduction pathways

Cross-talk can be defined as an interaction of two or more signaling pathways. The interaction of these signaling pathways via common components can cause the same response to different stimuli or alternatively different signaling pathways could interact and affect negatively or positively each other's outcome. Although the participation of CDPKs in different signaling pathways is relatively well

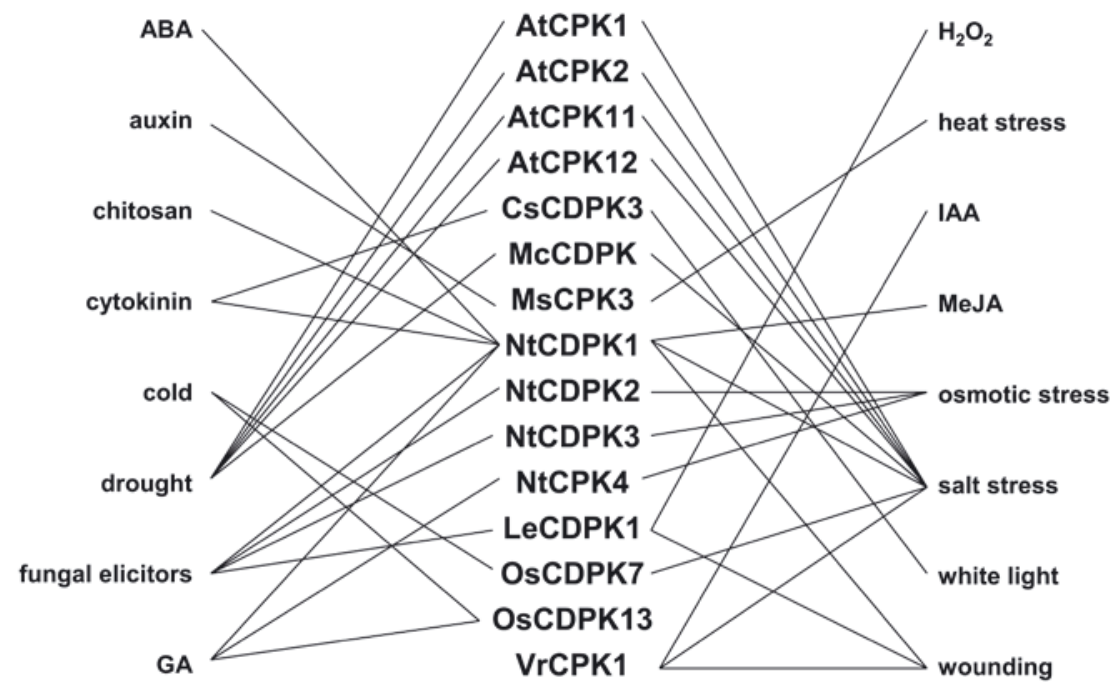

Figure 3. Cross-talk of signaling pathways involving CDPKs.

AtCPK1, AtCPK2, AtCPK10, AtCPK11 are from Arabidopsis (Urao et al., 1994); CpCPK1 is from zucchini (Ellard-Ivey et al., 1999); CsCDPK3 is from cucumber (Ullanat \& Javabaskaran, 2002); LeCDPK1 is from tomato (Chico et al., 2002); McCDPK1 is from crystalline ice plant (Patharkar \& Cushman, 2000); MsCPK3 is from alfalfa (Davletova et al., 2001); NtCDPK1, NtCDPK2, NtCDPK3, NtCPK4 are from tobacco (Yoon et al., 1999; Romeis et al., 2001; Zhang et al., 2005); OsCDPK7, OsCDPK13 are from rice (Saijo et al., 2000; Yang et al., 2003; Abbasi et al., 2004); VrCPK1 is from mung bean (Botella et al., 1996); (modified from Ludwig et al., 2004). 
documented (Fig. 3) still little is known about their role in the cross-talk between these pathways. Furthermore, considering the presence of many different CDPK isoforms induced by specific calcium signatures differently localized in the cell, triggered by different stimuli, this cross-talk is very complex and hard to elucidate. NtCDPK2 illustrates this complexity. NtCDPK2 is considered to be the integrating part of two different pathways activated by both hypo-osmotic stress and by pathogen attack (Cladosporium fulvum) (Romeis et al., 2001). Depending on the stress stimuli, NtCDPK2 activation varies in strength and duration. It seems that a short and weak activation of the enzyme after osmotic stress solely results in the induction of the wound signaling pathway, whereas a much stronger and sustained elicitation may lead to a plant defense response. Other CDPKs are also thought to function as cross-talk mediators between different pathways. For example, NtCDPK1 is induced not only by wounding but also by phytohormone treatment, high salt or fungal elicitors (Lee et al., 2003). A reduced level of NtCDPK1 in N. benthamiana plants results in severe abnormalities in cell morphology, spontaneous necrotic lesions and increased expression of marker genes for the plant defense response (PR1a, SAR8.2a and HIN1). It has been proposed that NtCDPK1 receives hormone signals to regulate cell division and differentiation. Overexpression of OsCDPK7 conferred both cold and salt/drought tolerance to rice plants (Saijo et al., 2000). Interestingly, OsCDPK7 overexpression enhanced only the transcription of the salt- and drought-responsive, but not the cold-responsive, target genes. Thus, it was suggested that cold and salt/drought tolerance are promoted through distinct pathways which can cross-talk via OsCDPK7.

In conclusion, the CDPKs are points of convergence that enable signal integration at different levels and provide appropriate downstream responses (Ludwig et al., 2004).

The major challenge for the future will be to elucidate the functions of CDPKs in particular signaling pathways and also in the cross-talk in the complex signaling network. To achieve this goal CDPK studies should combine traditional biochemical methods with molecular biology technologies. Studies concerning the effects of different stress stimuli, the character of calcium signatures activating the enzymes and potential targets of CDPKs should help to understand plant signal transduction.

\section{Acknowledgements}

The work was supported by grants: KBN Nr. 3P06A 00825 and PBZ-KBN-110/P04/21.

\section{REFERENCES}

Abbasi F, Onodera H, Toki S, Tanaka H, Komatu S (2004) OsCDPK13, a calcium-dependent protein kinase gene from rice, is induced by cold and gibberellin in rice leaf sheath. Plant Mol Biol 55: 541-552.

Abo-El-Saad M, Wu R (1995) A rice membrane calcium-dependent protein kinase is induced by gibberellin. Plant Physiol 108: 787-793.

Allwood EG, Smertenko AP, Hussey PJ (2001) Phosphorylation of plant actin-depolymerising factor by calmodulin-like domain protein kinase. FEBS Lett 499: 97-100.

Anil VS, Rao SK (2000) Calcium-mediated signaling during sandalwood somatic embryogenesis. Role for exogenous calcium as second messenger. Plant Physiol 123: 1301-1311.

Anil VS, Rao SK (2001) Purification and characterization of a $\mathrm{Ca}^{2+}$-dependent protein kinase from sandalwood (Santalum album L.): evidence for $\mathrm{Ca}^{2+}$-induced conformational changes. Phytochemistry 58: 203-212.

Asano T, Kunieda N, Omura Y, Ibe H, Kawasaki T, Takano M, Sato M, Furuhashi H, Mujin T, Takaiwa F, et al. (2002) Rice SPK, a calmodulin-like domain protein kinase, is required for storage product accumulation during seed development: phosphorylation of sucrose synthase is a possible factor. Plant Cell 14: 619-628.

Barker LDP, Templeton MD, Ferguson IB (1998) A 67-kDa plasma-membrane-bound $\mathrm{Ca}^{2+}$-stimulated protein $\mathrm{ki}$ nase active in sink tissue of higher plants. Planta 205: 197-204.

Berkowitz G, Zhang X, Mercier R, Leng Q, Lawton M (2000) Co-expression of a calcium-dependent protein kinase with inward rectified guard cell $\mathrm{K}^{+}$channel KAT1 alters current parameters in Xenopus laevis oocytes. Plant Cell Physiol 41: 785-790.

Botella JR, Arteca JM, Somodevilla M, Arteca RN (1996) Calcium-dependent protein kinase gene expression in response to physical and chemical stimuli in mungbean (Vigna radiata). Plant Mol Biol 30: 1129-1137.

Camoni L, Harper JF, Palmgren MG (1998) 14-3-3 proteins activate a plant calcium-dependent protein kinase (CDPK). FEBS Lett 430: 381-384.

Chaudhuri S, Seal A, Dasgupta M (1999) Autophosphorylation-dependent activation of calcium-dependent protein kinase from groundnut. Plant Physiol 120: 859-866.

Cheng S-H, Sheen J, Gerrish C, Bolwell GP (2001) Molecural identification of phenylalanine ammonia-lyase as a substrate of a specific constitutively active Arabidopsis CDPK expressed in maize protoplasts. FEBS Lett 503: 185-188.

Cheng S-H, Willmann MR, Chen H-Ch, Sheen J (2002) Calcium signaling through protein kinases. The Arabidopsis calcium-dependent kinase gene family. Plant Physiol 129: 469-485.

Cheong YH, Chang H-S, Gupta R, Wang X, Zhu T, Luan $S$ (2002) Transcriptional profiling reveals novel interactions between wounding, pathogen, abiotic stress, and hormonal responses in Arabidopsis. Plant Physiol 129: 661-677.

Chico JM, Raíces M, Téllez-Iñón MT, Ulloa RM (2002) A calcium-dependent protein kinase is systemically induced upon wounding in tomato plants. Plant Physiol 128: $256-270$.

Christodoulou J, Malmendal A, Harper JF, Chazin WJ (2004) Evidence for differing roles for each lobe of the calmodulin-like domein in a calcium-dependent protein kinase. J Biol Chem 279: 29092-29100. 
Dammann Ch, Ichida A, Hong B, Romanowsky SM, Hrabak EM, Harmon AC, Pickard BG, Harper JF (2003) Subcellular targeting of nine calcium-dependent protein kinase isoforms from Arabidopsis. Plant Physiol 132: 1840-1848.

Davletova S, Mészáros T, Miskolczi P, Oberschall A, Török K, Maryar Z, Dudits D, Deák M (2001) Auxin and heat shock activation of a novel member of the calmodulin like domain protein kinase gene family in cultured alfalfa cells. J Exp Bot 52: 215-221.

Douglas P, Moorhead G, Hong Y, Morrice N, MacKintosh $C$ (1998) Purification of a nitrate reductase kinase from Spinacea aleracea leaves, and its identification as a calmodulin-domain protein kinase. Planta 206: 435-442.

Ellard-Ivey M, Hopkins RB, White TJ, Lomax TL (1999) Cloning, expression and N-terminal myristoylation of CpCPK1, a calcium-dependent protein kinase from zucchini (Cucurbita pepo L.). Plant Mol Biol 39: 199-208.

Estruch JJ, Kadwell S, Merlin E, Crossland L (1994) Cloning and characterization of maize pollen-specific calcium-dependent calmodulin-independent protein kinase. Proc Natl Acad Sci USA 91: 8837-8841.

Evans NH, McAinsh MR, Hetherington AM (2001) Calcium oscillations in higher plants. Curr Plant Biol 4: 415-420.

Farmer PK, Choi JM (1999) Calcium and phospholipid activation of recombinant calcium-dependent protein kinase (DcCPK1) from carrot (Daucus carota L.) Biochim Biophys Acta 1434: 6-17.

Ganguly S, Singh M (1998) Characterization of a second calcium-dependent protein kinase from winged bean. Phytochemistry 48: 61-70.

Ganguly S, Singh M (1999) Purification and characterization of a protein phosphatase from winged bean. Phytochemistry 52: 239-246.

Grabski S, Arnoys E, Busch B, Schindler M (1998) Regulation of actin tension in plant cells by kinases and phosphatases. Plant Physiol 116: 279-290.

Grover M, Sharma AK, Dhingra A, Maheshwari SC, Tyagi AK (1998) Regulation of plastid gene expression in rice involves calcium and protein phosphatases/kinases for signal transduction. Plant Science 137: 185-190.

Harmon AC (2003) Calcium-regulated protein kinases of plants. Gravitational Space Biol Bull 16: 83-90.

Harmon AC, Lee J-Y, Yoo BC, Shao J (1996) Plant membrane-associated protein kinases. In: Membranes: Specialized Functions in Plant Cells (Smallwood M ed.) pp 137-150, Bios Scientific Publishers, Oxford.

Harmon AC, Gribskov M, Harper JF (2000) CDPKs-a kinase for every signal? Trends Plant Sci 5: 154-159.

Harmon AC, Gribskov M, Gubrium E, Harper JF (2001) The CDPK superfamily of protein kinases. New Phytologist 151: 175-183.

Harper JF, Harmon AC (2005) Plants, symbiosis and parasites: a calcium signaling connection. Nat Rev Mol Cell Biol 6: 555-566.

Harper JF, Binder BM, Sussman MR (1993) Calcium and lipid regulation of an Arabidopsis protein kinase expressed in Escherichia coli. Biochemistry 32: 3282-3290.

Harper JF, Breton G, Harmon AC (2004) Decoding Ca ${ }^{2+}$ signals through plant protein kinases. Annu Rev Plant Biol 55: 263-288.

Hegeman AD, Rodriguez M, Han B-W, Uno Y, Phillips GN Jr, Hrabak EM, Cushman JC, Harper JF, Harmon AC, Sussman MR (2006) A phyloproteomic characterization of in vitro autophosphorylation in calcium-dependent protein kinases. Proteomics 6: 3649-3664.

Hepler PK, Vidali L, Cheung AY (2001) Polarized cell growth in higher plants. Annu Rev Cell Dev Biol 17: 159-187.
Hrabak EM, Chan CWM, Gribskov M, Harper JF, Choi JH, Halford N, Kudla J, Luan S, Nimmo HG, Sussman MR, Thomas M, Walker-Simmons K, Zhu J-K, Harmon A C (2003) The Arabidopsis CDPK-SnRK superfamily of protein kinases. Plant Physiol 132: 666-680.

Huang JZ, Huber SC (2001) Phosphorylation of synthetic peptides by a CDPK and plant SNF-1-related protein kinase. Influence of proline and basic amino acid residues at selected positions. Plant Cell Physiol 42: 10791087.

Huang JZ, Hardin SC, Huber SC (2001) Identification of a novel phosphorylation motif for CDPKs: phosphorylation of synthetic peptides lacking basic residues at P3/P-4. Arch Biochem Biophys 393: 61-66.

Huber SC, Hardin SC (2004) Numerous posttranslational modifications provide opportunities for the intricate regulation of metabolic enzymes at multiple levels. Curr Opin Plant Biol 7: 318-322.

Hwang I, Sze H, Harper JF (2000) A calcium-dependent protein kinase can inhibit a calmodulin-stimulated $\mathrm{Ca}^{2+}$ pump (ACA2) located in the endoplasmic reticulum of Arabidopsis. Proc Natl Acad Sci USA 97: 6224-6229.

Jaworski K, Szmidt-Jaworska A, Tretyn A, Koncewicz J (2003) Biochemical evidence for a calcium-dependent protein kinase from Pharbitis nil and its involvement in photoperiodic flower induction. Phytochemistry 62: 1047-1055.

Kawasaki H, Nakayama S, Kretsinger RH (1998) Classification and evolution of EF-hand proteins. Biometals 11: 277-295.

Knight H, Knight MR (2000) Imaging spatial and cellular characteristics of low temperature calcium signature after cold acclimation in Arabidopsis. J Exp Bot 51: 16791686.

Knight H, Knight MR (2001) Abiotic stress signaling pathways: specificity and cross-talk. Trends Plant Sci 6: 262267.

Knight H, Trewavas AJ, Knight MR (1996) Cold calcium signaling in Arabidopsis involves two cellular pools and a change in calcium signature after acclimation. Plant Cell 8: 489-503.

Komatsu S, Li W, Konishi H, Yoshikawa M, Konisi T, Yang G (2001) Characterization of a $\mathrm{Ca}^{2+}$-dependent protein kinase from rice root: differential response to cold and regulation by abscisic acid. Biol Pharm Bull 24: 1316-1319.

Kuntz C, Chang A, Faure JD, Clarke AE, Polya GM, Anderson MA (1996) Phosphorylation of a style S-RNases by $\mathrm{Ca}^{2+}$-dependent protein kinases from pollen tubes. Sex Plant Reprod 9: 25-34.

Kwak S-H, Lee S-H (1997) The requirements for $\mathrm{Ca}^{2+}$, protein phosphorylation, and dephosphorylation for ethylene signal transduction in Pisum sativum L. Plant Cell Physiol 38: 1142-1149.

Lanteri ML, Pagnussat GC, Lamattina L (2006) Calcium and calcium-dependent protein kinases are involved in nitric oxide- and auxin-induced adventitious root formation in cucumber. J Exp Bot 57: 1341-1351.

Lee J-Y, Yoo BC, Harmon AC (1998) Kinetic and calciumbinding properties of three calcium-dependent protein kinase isoenzymes from soybean. Biochemistry 37: 6801-6809.

Lee SS, Cho HS, Yoon GM, Ahn J-W, Kim H-H, Pai H-S (2003) Interaction of NtCDPK1 calcium-dependent protein kinase with NtRpn regulatory subunit of the $26 \mathrm{~S}$ proteasome in Nicotiana tabacum. Plant J 33: 825-840.

León J, Rojo E, Sánchez-Serrano JJ (2001) Wound signalling in plants. J Exp Bot 52: 1-9. 
Li WG, Komatsu S (2000) Cold-induced calcium-dependent protein kinase(s) in rice (Oryza sativa L.) seedling stem tissues. Theor Appl Genet 101: 355-363.

Li J, Lee YR, Assmann SM (1998) Guard cells posses a calcium-dependent protein kinase that phosphorylates the KAT1 potassium channel. Plant Physiol 116: 785-795.

Loog M, Toomik R, Sak K, Muszyńska G, Järv J, Ek P (2000) Peptide phosphorylation by calcium-dependent protein kinase from maize seedlings. Eur J Chem 267: 337-343.

Lu SX, Hrabak EM (2002) An Arabidopsis calcium-dependent protein kinase is associated with the endoplasmic reticulum. Plant Physiol 128: 1008-1021.

Ludwig AA, Romeis T, Jones JDG (2004) CDPK-mediated signalling pathways: specificity and cross-talk. J Expl Bot 55: 181-188.

Ludwig AA, Hiromasa S, Felix G, Fraymark G, Miersz O, Wasternack C, Boller T, Jones JDG, Romeis T (2005) Ethylene-mediated cross-talk between calcium-dependent protein kinase and MAPK signalling controls stress responses in plants. Proc Natl Acad Sci USA 102: 10736-10741.

MacIntosh GC, Ulloa RM, Raíces M, Téllez-Iñón MT (1996) Changes in calcium-dependent protein kinase activity during in vitro tuberization in potato. Plant Physiol 112: 1541-1550.

Maréchal E, Hiratsuka K, Delgado J, Nairn A, Qin J, Chait BT, Chua N-H (1999) Modulation of GT-1 DNA-binding activity by calcium-dependent phosphorylation. Plant Mol Biol 40: 373-386.

Martin ML, Busconi L (2001) A rice membrane-bound calcium-dependent protein kinase is activated in response to low temperature. Plant Physiol 125: 1442-1449.

McCubbin AG, Ritchie SM, Swanson SJ, Gilroy S (2004) The calcium-dependent protein kinase HvCDPK1 mediates the gibberellic acid response of the barley aleurone through regulation of vacuolar functions. Plant $J$ 39: 206-218.

McMichael RW Jr, Bachmann M, Huber SC (1995a) Spinach leaf sucrose-phosphate synthase and nitrate reductase are phosphorylated/inactivated by multiple protein kinases in vitro. Plant Physiol 108: 1077-1082.

McMichael RW Jr, Kochansky J, Klein RR, Huber SC (1995b) Characterization of the substrate specificity of sucrose-phosphate synthase protein kinase. Arch Biochem Biophys 321: 71-75.

Meshi T, Moda I, Minami M, Okanami M, Iwabuchi M (1998) Conserved Ser residues in the basic region of the bZIP-type transcription factor HBP-1a(17): importance in DNA binding and possibile targets for phosphorylation. Plant Mol Biol 36: 125-136.

Moorhead G, Douglas P, Cotelle V, Harthill J, Morrice N, Meek S, Deiting U, Stitt M, Scarabel M, Aitken A, MacKintosh C (1999) Phosphorylation-dependent interactions between enzymes of plant metabolism and 143-3 proteins. Plant J 18: 1-12.

Morello L, Frattini M, Giani S, Christou P, Breviario D (2000) Overexpression of the calcium-dependent protein kinase OsCDPK2 in transgenic rice is expressed by light in leaves and disrupts seed development. Transgenic Res 9: 453-462.

Moutinho A, Trewavas AJ, Malhó R (1998) Relocation of $\mathrm{Ca}^{2+}$-dependent protein kinase activity during pollen tube reorientation. Plant Cell 10: 1499-1509.

Murillo I, Jaeck E, Cordero J, San Segundo B (2001) Transcriptional activation of maize calcium-dependent protein kinase gene in response to fungal elicitors and infection. Plant Mol Biol 45: 145-158.
Nakai T, Konishi T, Zhang XQ, Chollet R, Tonouchi N, Tsuchida T, Yoshinaga F, Mori H, Sakai F, Hayashi T (1998) An increase in apparent affinity for sucrose of mung bean sucrose synthase is coused by in vitro phosphorylation or directed mutagenesis of Ser 11. Plant Cell Physiol 39: 1337-1341.

Neumann GM, Thomas I, Polya GM (1996) Identification of the site on potato carboxy peptidase inhibitor that is phosphorylated by plant calcium-dependent protein kinase. Plant Science 114: 45-51.

Ogawa N, Yabuta N, Ueno Y, Izui K (1998) Characterization of a maize $\mathrm{Ca}^{2+}$-dependent protein kinase phosphorylating phosphoenolpyruvate carboxylase. Plant Cell Physiol 39: 1010-1019.

Patharkar OR, Cushman JC (2000) A stress-induced calcium-dependent protein kinase from Mesembryanthemum crystallinum phosphorylates a two-component pseudoresponse regulator. Plant J 24: 679-691.

Patharkar OR, Cushman JC (2006) A novel coiled-coil protein co-localizes and interacts with a calcium-dependent protein kinase in the common ice plant during low-humidity stress. Planta 225: 57-73.

Raices M, Gargantini PR, Chinchilla D, Crespi M, TéllezIñón MT, Ulloa RM (2003) Regulation of CDPK isoforms during tuber development. Plant Mol Biol 52: 1011-1024.

Ramachandiran S, Takezawa D, Wang W, Poovaiah BW (1997) Functional domains of plant chimeric calcium/ calmodulin-dependent protein kinase: regulation by autoinhibitory and visinin-like domains. Biochem J 121: 984-990.

Reddy VS, Reddy ASN (2004) Proteomics of calcium-signaling components in plants. Phytochemistry 65: 17451776.

Roberts DM, Harmon AC (1992) Calcium-modulated proteins-targets of intracellular calcium signals in higher plants. Annu Rev Plant Physiol Mol Biol 43: 375-414.

Rojo E, León J, Sánchez-Serrano JJ (1999) Cross-talk between wound signalling pathways determines local versus systemic gene expression in Arabidopsis thaliana. Plant J 20: 135-142.

Romeis T, Piedras P, Jones JDG (2000) Resistance genedependent activation of a calcium-dependent protein kinase in the plant defense response. Plant Cell 12: 803-815.

Romeis T, Ludwig AA, Martin R, Jones JDG (2001) Calcium-dependent protein kinases play an essential role in a plant defence. EMBO J 20: 5556-5567.

Rudd JJ, Franklin-Tong VE (2001) Unravelling responsespecificity in $\mathrm{Ca}^{2+}$ signaling pathways in plant cells. New Phytologist 151: 7-33.

Saha P, Singh M (1995) Characterization of a winged bean (Psophocarpus tetragonolobus) protein kinase with calmodulin-like domain: regulation by autophosphorylation. Biochem J 305: 205-210.

Saijo Y, Hata S, Sheen J, Izui K (1997) cDNA cloning and prokaryotic expression of maize calcium-dependent protein kinases. Biochim Biophys Acta 1350: 109-114.

Saijo Y, Hata S, Kyozuka J, Shimanoto K, Izui K (2000) Over-expession of a single $\mathrm{Ca}^{2+}$-dependent protein kinase confers both cold and salt/drought tolerance on rice plants. Plant J 23: 319-327.

Sano T, Higaki T, Handa K, Kadota Y, Kuchitsu K, Hasezawa S, Hoffmann A, Endter J, Zimmermann U, Hedrich R, Roitsch T (2006) Calcium ions are involved in the delay of plant cell cycle progression by abiotic stresses. FEBS Lett 580: 597-602.

Sanders D, Pelloux J, Brownlee C, Harper JF (2002) Calcium at the crossroads of signaling. Plant Cell S401-S417. 
Schaller GE, Harmon AC, Sussman MR (1992) Characterization of a calcium- and lipid-dependent protein kinase associated with the plasma membrane of oat. Biochemistry 31: 1721-1727.

Sebastià CH, Hardin SC, Clouse SD, Kieber JJ, Huber SC (2004) Identification of a new motif for CDPK phosphorylation in vitro that suggests ACC synthase may be a CDPK substrate. Arch Biochem Biophys 428: 81-91.

Sehnke PC, Rosenquist M, Alsterfjord M, De Lille J, Sommarin M, Larsson C, Ferl RJ (2002) Evolution and isoform specificity of plant 14-3-3 proteins. Plant Mol Biol 50: 1011-1018.

Sharma VK, Jain PK, Malik MK, Maheshwari SC, Khurana JP (1997) Light- and calcium-modulated phosphorylation of proteins from wheat seedlings. Phytochemistry 44: 781-786.

Sharma A, Matsuoka M, Tanaka H, Komatu S (2001) Antisense inhibition of a BRI1 receptor reveals additional protein kinase signaling components downstream to the perception of brassinosteroids in rice. FEBS Lett 507: 346-350.

Smertenko AI, Jiang Ch-J, Simmons NJ, Weeds AG, Davies DR, Hussey PJ (1998) Ser6 in the maize actin-depolymerizing factor, ZmADF3, is phosphorylated by calcium-stimulated protein kinase and is essential for the control of functional activity. Plant J 14: 187-193.

Szczegielniak J, Liwosz A, Jurkowski I, Loog M, Dobrowolska G, Ek P, Harmon AC, Muszyńska G (2000) Calcium-dependent protein kinase from maize seedlings activated by phospholipids. Eur J Biochem 267: 3818-3827.

Szczegielniak J, Klimecka M, Liwosz A, Ciesielski A, Kaczanowski S, Dobrowolska G, Hormon AC, Muszyńska G (2005) A wound-responsive and phospholipid-regulated maize calcium-dependent protein kinase. Plant Physiol 139: 1970-1983.

Tähtiharju S, Sangwan V, Monroy AF, Dhindsa RS, Borg M (1997) The induction of kin genes in cold-acclimat- ing Arabidopsis thaliana. Evidence of a role for calcium. Planta 203: 442-447.

Ullanat R, Javabaskaran C (2002) Distinct light-, cytokininand tissue-specific regulation of calcium dependent protein kinase gene expression in cucumber (Cucumber sativus). Plant Sci 162: 153-163.

Urao T, Katagiri T, Mizoguchi T, Yamaguchi-Shinozaki K, Hayashida N, Shinozaki K (1994) Two genes that encode $\mathrm{Ca}^{2+}$-dependent protein kinases are induced by drought and high-salt stresses in Arabidopsis thaliana. Mol Gen Genet 244: 331-340.

Watillon B, Kettman R, Boxus P, Burny A (1993) A calcium/calmodulin-binding serine/threonine protein kinase homologous to the mammalian type II calcium/ calmodulin protein kinase is expressed in plant cells. Plant Physiol 101: 1381-1384.

Yang W, Boss WF (1994) Regulation of phosphatidylinositol 4-kinase by protein activator PIK-A49. J Biol Chem 269: 3852-3857.

Yang G, Shen S, Yang S, Komatsu S (2003) OsCDPK13, a calcium-dependent protein kinase gene from rice, is induced in response to cold and gibberellin. Plant Physiol Biochem 41: 369-374.

Yoon GM, Cho HS, Ha HJ, Liu JR, Lee HP (1999) Characterization of NtCDPK1, a calcium-dependent protein kinase gene in Nicotiana tabacum, and the activity of its encoded protein. Plant Mol Biol 39: 991-1001.

Yu X-Ch, Li M-J, Gao G-F, Feng H-Z, Geng X-Q, Peng ChC, Zhu S-Y, Wang X-J, Shen Y-Y, Zhang D-P (2006) Abscisic acid stimulates a calcium-dependent protein kinase in grape berry. Plant Physiol 140: 558-579.

Zhang XQ, Chollet R (1997) Seryl-phosphorylation of soybean nodule sucrose synthase (nodulin-100) by a $\mathrm{Ca}^{2+}$ dependent protein kinase. FEBS Lett 410: 126-130.

Zhang M, Liang S, Lu Y-T (2005) Cloning and functional characterization of NtCPK4, a new tobacco calcium-dependent protein kinase. Bioch Biophys Acta 1729: 174185. 